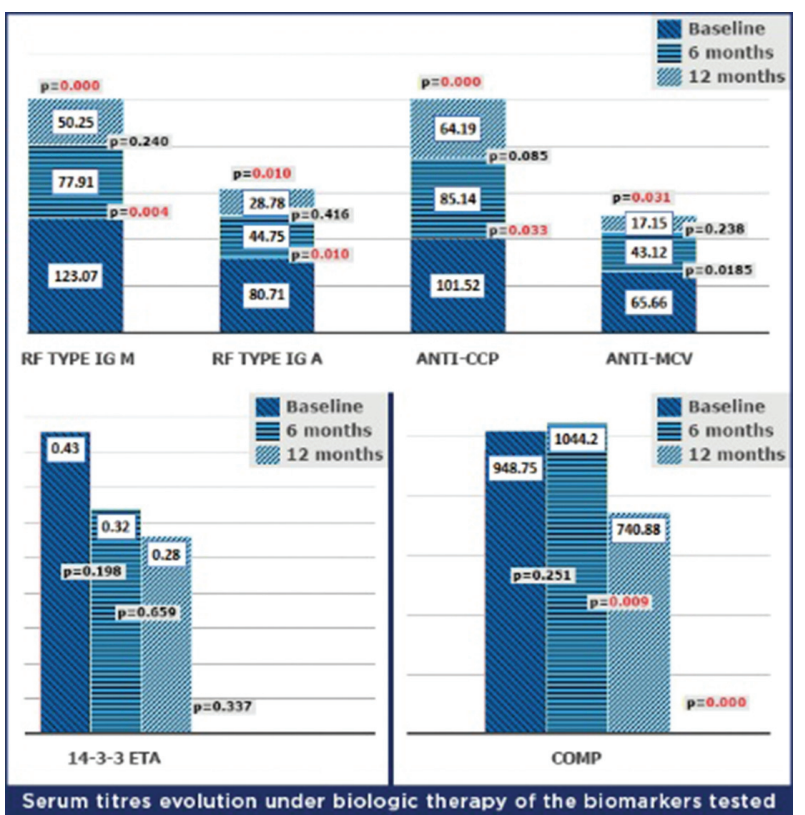

Conclusions: in the future a version using multiple biomarkers could increase accuracy for identifying pretreatment patients who will respond to anti-TNF therapy. Smoking has a negative impact on the response to biologic treatment. Disclosure of Interest: None declared

DOI: 10.1136/annrheumdis-2018-eular.5690

\section{FRI0105 CONCOMITANT USE OF CORTICOSTEROIDS AT THE BASELINE DOES NOT AFFECT THE DRUG SURVIVAL OF ABATACEPT IN RHEUMATOID ARTHRITIS}

S.S. KOCA ${ }^{1}$, B. Öz ${ }^{1}$, A. Karatas ${ }^{1}$, H.E. Dalkılıç ${ }^{2}$, G. Can $^{3}$, Y. Pehlivan ${ }^{2}$, S. Senel ${ }^{4}$, A. Yazıc ${ }^{5}$, N. İnanç ${ }^{6}$, A. Çefle ${ }^{5}$, Z. Ertürk ${ }^{6}$, S. Akar ${ }^{7}$, B. Yagiz ${ }^{2}$, B. Göker ${ }^{8}$, A. M. Birlik ${ }^{3}$, F. Önen ${ }^{3} .{ }^{1}$ Rheumatology Department, Firat University, Elazığ; ${ }^{2}$ Rheumatology Department, Uludağ University, Bursa; ${ }^{3}$ Rheumatology Department, Dokuz Eylül University, Izmir, ${ }^{4}$ Rheumatology Department, Erciyes University, Kayseri; ${ }^{5}$ Rheumatology Department, Kocaeli University, Kocaeli; ${ }^{6}$ Rheumatology Department, Marmara University, İstanbul; ${ }^{7}$ Rheumatology Department, Katip Çelebi University, Izmir, ${ }^{8}$ Rheumatology Department, Gazi University, Ankara, Turkey

Background: Rheumatoid arthritis (RA) is a chronic inflammatory disease leading to deformities and disabilities. in the treatment of RA glucocorticoids are selected sometimes to relief symptoms and to increase compliance for treatment. Objectives: The purpose of our study is to investigate whether concomitant glucocorticoid treatment at the baseline affects drug survival for abatacept treatment in RA.

Methods: Data on patient characteristics, diagnosis, previous treatment and outcomes have been collected since 2011 in Turkish Biologic (TURKBIO) Registry. By the end of December 2017, 338 RA patients, received abatacept from the TURKBIO registry, were included in the analysis. Patients were divided into groups according to the use of glucocorticoid when abatacept therapy was started. Demographic and clinical data including age, sex, disease type, disease duration, and previous or current treatment with DMARDs and biological drug durations are recorded in the database. Kaplan-Meier survival analysis was performed to estimate the drug survival. Subgroups were compared by log-rank.

Results: There were no significant differences in age, gender, seropositivity, tender and swollen joint counts at baseline in the study groups. The disease duration was higher in the glucocorticoid users $(p=0.001)$. Abatacept was the first choice bDMARDs in the $44.5 \%$ of glucocorticoid users while it was $68.6 \%$ in the glucocorticoid non-users $(\mathrm{p}<0.001)$. In addition to abatacept, use of sDMARDs were $96.7 \%$ and $53.8 \%$ in the glucocorticoid users and non-users, respectively. Baseline VAS-pain and ESR were higher in the glucocorticoid non-users $(p=0.047$, $p=0.009$, respectively), but other baseline parameters were similar in glucocorticoid users and non-users. There was no difference between groups in terms of drug survival rates for abatacept (figure 1 ).
Abstract FRI0105 - Table 1. Clinical and laboratory characteristics

\begin{tabular}{lccc}
\hline & $\begin{array}{c}\text { Glucocorticoid non- } \\
\text { users }(\mathbf{n}=\mathbf{1 5 6})\end{array}$ & $\begin{array}{c}\text { Glucocorticoid users } \\
(\mathbf{n}=182)\end{array}$ & $\mathbf{p}$ \\
\hline Age, year & $56(47-64)$ & $57(47-63)$ & 0.827 \\
Gender (Females), $\mathbf{n}(\%)$ & $135(86.5)$ & $151(82.9)$ & 0.390 \\
Disease duration, years & $10(5-15)$ & $13(8-18)$ & $\mathbf{0 . 0 0 1}$ \\
1 st choice bDMARs is & $68.6 \%$ & $44.5 \%$ & $<\mathbf{0 . 0 0 1}$ \\
abatacept,\% & & & \\
Concomitant sDMARD & $53.8 \%$ & $96.7 \%$ & $<\mathbf{0 . 0 0 1}$ \\
usage,\% & & & \\
RF positivity, $\mathbf{n}$ (\%) & 68.1 & 65.8 & 0.735 \\
CCP positivity, $\mathbf{n}$ (\%) & 61.8 & 66.7 & 0.485 \\
Baseline ESR, mm/h & $38(24-55)$ & $28(18-44)$ & $\mathbf{0 . 0 0 9}$ \\
12th month ESR, mm/h & $33(20-50)$ & $27(16-39)$ & 0.155 \\
Baseline CRP, mg/dl & $12(5-21)$ & $12(4.89-30.9)$ & 0.870 \\
12th month CRP, mg/dl & $4(3-8)$ & $9(3-19)$ & $\mathbf{0 . 0 2 0}$ \\
Baseline DAS28-CRP & $4.95(4.2-5.4)$ & $4.8(3.9-5.35)$ & 0.123 \\
12th month DAS28-CRP & $2.05(1.7-2.9)$ & $2.6(2.1-3.9)$ & $\mathbf{0 . 0 0 2}$ \\
Baseline CDAl & $22(13.8-28.3)$ & $19.8(13.2-27)$ & 0.278 \\
12th month CDAl & $3.2(2-7.95)$ & $6.3(3-10.7)$ & 0.061 \\
\hline
\end{tabular}

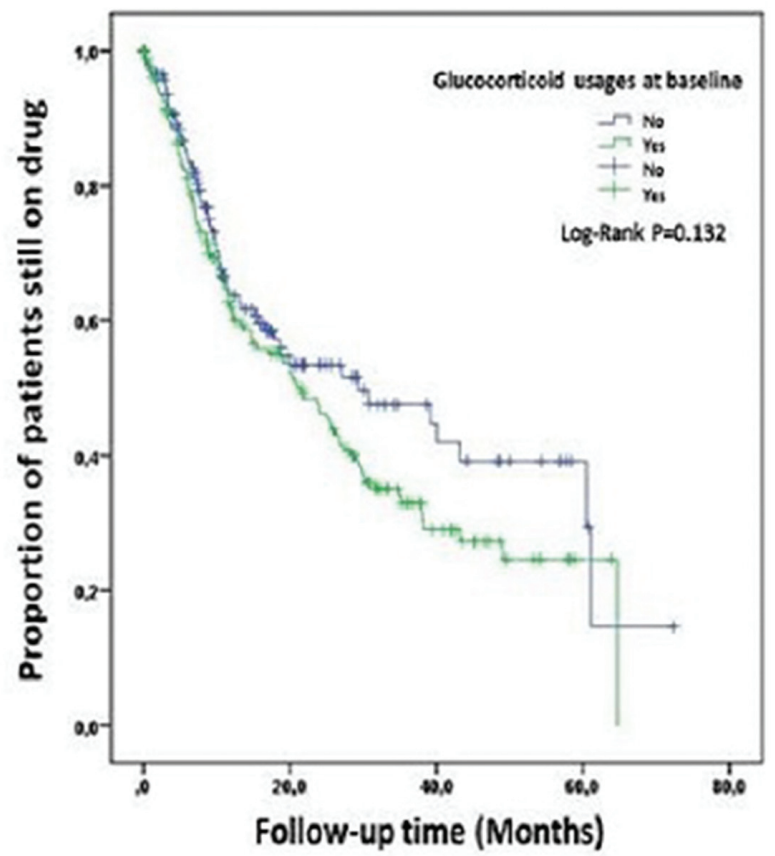

Abstract FRI0105 - Figure 1. Drug survival curve in glucocorticoid user and non-use patients

Conclusions: When abatacept treatment started, concomitant use of glucocorticoid at the baseline could not significantly alter drug survival for abatacept in the RA.

Disclosure of Interest: None declared

DOI: 10.1136/annrheumdis-2018-eular.5819

\section{FRI0106 IMPACT OF BIOLOGICAL AND TARGETED SYNTHETIC DMARDS ON WORK IN PATIENTS WITH CHRONIC INFLAMMATORY ARTHRITIS : A META ANALYSIS OF RANDOMISED CONTROLLED TRIALS AND CONTROLLED COHORTS}

C. Traverson ${ }^{1}$, A. tubery ${ }^{1}$, C. Hua ${ }^{1}$, F. Barchechath-Flaisler' ${ }^{1}$, C. Lukas ${ }^{2,3}$ B. Combe ${ }^{2}$, J. Morel ${ }^{2}$, C. Gaujoux-Viala ${ }^{1,4} .{ }^{1}$ Rheumatology, Nîmes University Hospital, Nimes; ${ }^{2}$ Rheumatology, Montpellier University Hospital; ${ }^{3}$ Rheumatology, CHU Lapeyronie and EA2415, Montpellier University, Montpellier, ${ }^{4}$ Rheumatology, Hospital and EA2415 Montpellier University, Nîmes, France

Background: The addition of biological (b) and new targeted synthetic (ts) DMARDs agents in chronic inflammatory arthritis (CIAs) therapeutic strategies 
has improved the possibility of controlling disease activity and slowing the pro gression of joint damage. However their impact on work participation is unclear. Objectives: To assess the effect of biological and tsDMARDs versus conven tional treatments in patients with CIAs on work outcomes : employment, presenteeism and absenteeism

Methods: A systematic review of the literature using Pubmed-Medline and the Cochrane library was performed until January 2017. All randomised controlled trials (RCT) and controlled cohorts (CC) comparing work outcomes in patients with rheumatic diseases such as rheumatic arthritis (RA), ankylosing spondylarthris (AS) and psoriatic arthritis (PsA) treated with biological or tsDMARDs versus conventional therapies were selected. Statistical analysis determined in each study effect size (ES) or odds-ratios (OR) as appropriate to assess the magnitude of treatment effect. Pooled ES and OR were computed by meta-analysis. A random effect model was used in case of heterogeneity.

Results: Thirty six RCTs and eight CCs were analysed ie 12769 patients with conventional treatment and 19875 patients with bDMARD or tsDMARD (4619 Infliximab, 4629 Etanercept, 3872 Adalimumab, 670 Golimumab, 2101 Certolizumab, 691 Abatacept, 444 Sirukumab, 1668 Baricitinib, 672 Tofacitinib, 365 Sarilumab, 444 Sirukumab etc); 34 studies included 30423 patients with RA, 7 studies included 1496 patients with AS and 3 studies included 725 patients with PsA.

This meta-analysis showed in patients treated by bDMARD vs conventional treatment:

- a significant decrease of accumulated missed workdays at week 24: ES -0.34 IC95\%[-0.6; - 0.08] and at week 52: ES -0.04 IC95\% [-0.29;0.2],

- a significant decrease of patients loosing hours due to CIAs: RR 0.63 IC95\% [0.48; 0.83],

- a significant improvement in VAS productivity: ES - 1.81 IC95\%[-2.61; -1.01],

- For the employment loss, the positive effect of bDMARDs was nearly significant: OR 0.60 IC95\% [0.33; 1.09$]$.

Conclusions: Despite the heterogeneity of the data, this meta-analysis showed the beneficial effect of bDMARDs on both absenteeism and presenteeism in CIAs. Thus the high cost of biologic agents could be partly balanced with savings in indirect costs.

Disclosure of Interest: C. Traverson: None declared, A. tubery: None declared, C. Hua Consultant for: Pfizer, BMS, abbvie, F. Barchechath-Flaisler Consultant for: Roche Pharmaceuticals, C. Lukas Consultant for: Abbvie, BMS, Celgene, Janssen, MSD, Novartis, Pfizer, Sanofi, Schering, Roche- Chugai, UCB, B. Combe Grant/research support from: Pfizer, UCB, Consultant for: Abbvie, BMS, Janssen, Lilly, MSD, Novartis, Pfizer, Roche-Chugai, UCB, Speakers bureau: BMS, Janssen, Lilly, MSD, Pfizer, Roche-Chugai, UCB, J. Morel Consultant for: Abbvie, BMS, Celgene, Janssen, Medac, MSD, Novartis, Pfizer, Sanofi, Schering, Roche- Chugai, UCB, C. Gaujoux-Viala Grant/research support from: Pfizer, Consultant for: Abbvie, BMS, Celgene, Janssen, Medac, MSD, Nordic Pharma, Novartis, Pfizer, Sanofi, Roche- Chugai, UCB

DOI: 10.1136/annrheumdis-2018-eular.4839

\section{FRI0107 FIVE SUCCESSFUL PREGNANCIES WITH ANTENATAL ANAKINRA EXPOSURE}

C.J.F. Smith ${ }^{1}$, C. Chambers ${ }^{2} .{ }^{1}$ Rheumatology, Allergy, Immunology, ${ }^{2}$ Pediatrics, University of California San Diego, La Jolla, USA

Background: Current recommendations are to discontinue the interleukin-1 (IL1) inhibitor anakinra prior to pregnancy given lack of safety evidence. ${ }^{1} \mathrm{~A}$ total of 39 previous exposed pregnancies have been documented in the literature, and two resulting cases of fetal renal agenesis have been described. ${ }^{2,3}$

Objectives: Our aim is to add to the limited existing data on IL-1 inhibitor use in pregnancy.

Methods: Data were obtained from the Organisation of Teratology Information Specialists (OTIS) Autoimmune Disease in Pregnancy Project, a prospective cohort study of pregnancy outcomes in the U.S. and Canada. Eligible women enrolled prior to 19 weeks' gestation between 2004 and 2017. Women who consented to participate were interviewed two to three times during pregnancy with a standard questionnaire regarding medical history, exposures during pregnancy, and demographic characteristics. Outcomes were obtained by maternal interview and medical record abstraction.

Results: Five pregnancies with anakinra exposure were identified, all resulting in full-term singleton live births, mean gestational age at delivery of 38.9 weeks, with no major or long-term infant complications. Three maternal subjects used anakinra for adult-onset Still's disease (AOSD) and two for juvenile idiopathic arthritis (JIA). One mother was diagnosed with AOSD during pregnancy, and anakinra was started at 20 weeks' gestation. All other subjects had a known diagnosis prior to pregnancy, and four subjects used the medication into the third trimester. All maternal subjects used $100 \mathrm{mg}$ dosing of anakinra, four with daily use, one with weekly use. For all subjects who discontinued anakinra, some amount of steroid medication was necessary for treatment of disease flare. Two subjects developed oligohydramnios, one also with pregnancy-induced hypertension. Two women had caesarian sections, one medically-indicated and one scheduled. One infant had low birth weight, but follow-up records indicated normal adjusted weight at one year. Three women successfully breastfed their infants, at least two of whom continued anakinra while breastfeeding.

Conclusions: Anakinra was used successfully in five full term pregnancies. Two subjects developed oligohydramnios, however. With the two previous reported cases of fetal renal agenesis, a process leading to low fluid levels, and the fact that maternal hyperthermia has been previously linked to fetal renal anomalies, ${ }^{4}$ it is worth further exploring the potential link between anakinra use, uncontrolled maternal febrile disease, and fetal outcomes. These data add to the limited knowledge regarding antenatal anakinra use and support its use in pregnant women without access to effective alternative therapies that have a larger volume of reas suring safety data.

\section{REFERENCES}

[1] Götestam Skorpen C, et al. The EULAR points to consider for use of antirheumatic drugs before pregnancy, and during pregnancy and lactation. Ann Rheum Dis 2016;75:795-810.

[2] Chang Z, et al. Anakinra use during pregnancy in patients with cryopyrinassociated periodic syndromes (CAPS). Arthritis Rheumatol 2014;66:3227-32.

[3] Youngstein T, et al. International multi-centre study of pregnancy outcomes with interleukin-1 inhibitors. Rheumatology (Oxford). 2017;56:2102-2108.

[4] Abe K, et al. Maternal febrile illnesses, medication use, and the risk of congenital renal anomalies. Birth Defects Res A Clin Mol Teratol 2003;67:911-8.

Disclosure of Interest: None declared

DOI: 10.1136/annrheumdis-2018-eular.1849

\section{FRI0108 GOLIMUMAB IMPROVES WORK PRODUCTIVITY AND ACTIVITY AND QUALITY OF LIFE IN PATIENTS WITH RHEUMATOID ARTHRITIS (RA), PSORIASIS ARTHRITIS (PSA) AND AXIAL SPONDYLOARTHRITIS (AXSPA): INTERIM RESULTS FROM A NON-INTERVENTIONAL STUDY IN AUSTRIA (GO ACTIVE)}

C. Dejaco ${ }^{1}$, T. Mueller $^{2}$, O. Zamani ${ }^{3}$, U. Kurtz ${ }^{4}$, S. Egger ${ }^{5}$, J. Resch-Passini $^{6}$, A. Totzauer $^{7}$, W. Eisterer ${ }^{8}$, B. Yazdani-Biuki ${ }^{9}$, T. Schwingenschloegl ${ }^{10}$, P. Peich ${ }^{11}$, A. Kraus ${ }^{12}$, G.W. Naerr ${ }^{13}$, V. Rickert ${ }^{13}$. ${ }^{1}$ Medical University Graz; ${ }^{2}$ Private Office, Graz; ${ }^{3}$ Rheuma Zentrum Favoriten, Vienna; ${ }^{4}$ Rheuma Praxis Dr. Kurtz, Gleisdorf, ${ }^{5}$ Ordination Gesundheitsquadrat, ${ }^{6}$ Rheuma-Zentrum Wien-Oberlaa GmbH, Vienna ${ }^{7}$ Private Office Dr. Anna Totzauer, Gmünd; ${ }^{8}$ Klinikum-klagenfurt am Wörthersee, Klagenfurt, ${ }^{9}$ Dr. Schrenk and Dr. Yazdani-Biuki OG -Gruppenpraxis, Fürstenfeld; ${ }^{10}$ Private Office Dr. Thomas Schwingenschloegl, Wiener Neudorf, ${ }^{11}$ Private Office Prim. Univ. Doz. Dr. Peter Peichl, Vienna; ${ }^{12}$ Private Office Dr. Angelika Kraus, Melk; ${ }^{13}$ Merck Sharp and Dohme Gmbh, Ares Tower, Donau-City-Straße 11, 1220 Vienna, AUSTRIA, Vienna, Austria

Background: Golimumab has shown clinical efficacy and tolerability within its clinical trial program. No systemic outcome data regarding patient-reported outcomes and health economic parameters reflecting the real world use of golimumab in Austria are currently available.

Methods: Go Active is a prospective, non-interventional, multi-centre study in Austria. The impact of golimumab therapy on work productivity and activity (WPAI) and quality of life (RAQoL for RA patients, AsQoL for axSpA patients, PsAQoL for PsA patients) is assessed by using patient reported outcomes. Patients (target recruitment: $n=320$ ) are followed up to 2 years. For the current interim analysis (data cut-off: 18DEC2017) changes in the primary endpoint from baseline to month 3 were analysed in 167 patients.

Results: 167 patients are included in the current analysis ( 74 patients with RA, 49 patients with axSpA, and 44 patients with PsA). At study entry, most patients were biological-naïve and employed.

Median age at registration was 52 years (patients with RA: 57 years, patients with axSpA: 41 years, and patients with PsA: 44 years). Almost 2/3 of patients were female (84\% of patients with RA, $37 \%$ patients with axSpA, and $55 \%$ of patients with PsA). Most patients were biological-naïve at study entry $(77 \%$ of all patients $73 \%$ of patients with RA, $80 \%$ of patients with axSpA, and $82 \%$ of patients with PsA). $42 \%$ of patients were not employed (58\% of patients with RA, $29 \%$ of patients with axSpA, and $30 \%$ of patients with $\mathrm{SpA}$ ); $14 \%$ due to incapacity for work ( $12 \%$ of patients with RA, $21 \%$ of patients with axSpA, and $16 \%$ of patients with $\mathrm{SpA}$ ) and $54 \%$ due to age-related pension ( $60 \%$ of patients with RA, $21 \%$ of patients with axSpA, and $69 \%$ of patients with $\mathrm{SpA}$ ). Most of the patients, who worked for pay, worked full time. 159 of all patients and 66 of employed patients completed the WPAI questionnaire at baseline and after 3 months. Overall work productivity improved by -33 ( -40 for patients with $R A$, and -31 for patients with axSpA and PsA) and activity impairment by -30 ( -40 for patients with RA and 